\title{
Growth, Quality, and Economic Value Responses of Bedding Plants to Reduced Water Usage
}

\author{
Yanjun Guo, Terri Starman', and Charles Hall \\ Department of Horticultural Sciences, Texas A\&M University, 2133 TAMU, \\ College Station, TX 77843
}

Additional index words. drought stress, water, shelf life, postharvest

\begin{abstract}
This study analyzed the effects of two ranges of drying down of substrate moisture content (SMC) before re-watering on plant growth and development, postproduction quality, and economic value of bedding plants grown in 1.67- $\mathrm{L}$ containers during greenhouse production. The two SMC treatments were wide-range (WR) SMC (WR-SMC) for dry-down from container capacity (CC) of 54\% SMC dried down to $20 \%$ SMC or narrow-range (NR) SMC (NR-SMC) for dry-down from CC of $54 \%$ SMC dried down to $40 \%$ SMC. Six bedding plant cultivars were used [Solenostemon scutellarioides 'French Quarter' (coleus); Petunia $\times$ hybrida 'Colorworks Pink Radiance' (petunia); Lantana camara 'Lucky Flame' (lantana); Impatiens $\times$ hybrida 'Sunpatiens Compact Hot Coral' (SCC); 'Sunpatiens Spreading Lavender' (SSL) (impatiens); and Salvia splendens 'Red Hot Sally II' (salvia)]. Shoot dry weight was reduced with WR-SMC on petunia, lantana, impatiens SCC, and salvia at the end of production. With WR-SMC, the petunia and impatiens SCC root ball coverage percentages were greater on the bottom of the container, whereas those of impatiens SSL and salvia were reduced. The WR-SMC increased petunia postproduction quality by increasing the flower number. Lantana and impatiens SCC inflorescence/flower and/or bud number were reduced with WR-SMC. The impatiens SSL flower number was unaffected by SMC treatment. Salvia grown with WR-SMC had increased postproduction quality. WR-SMC reduced postproduction water potential in petunia, lantana, and coleus, suggesting that plants with WR-SMC during production were acclimated to reduced irrigation administered during postproduction. WR-SMC saved labor due to less frequent watering and overhead-associated costs due to reduced bench space, with the exception of coleus and impatiens SSL, which used the same bench space as NR-SMC. Considering production and/or postproduction quality, using WR-SMC during greenhouse production is beneficial as an irrigation method for coleus, petunia, impatiens SSL, and salvia, but not for impatiens SCC or lantana grown in 1.67-L containers.
\end{abstract}

The wholesale value of bedding and garden plants was $\$ 1.86$ billion in 2015 , which was $44 \%$ of the total wholesale value of floriculture crops in the United States, thus making bedding and garden plants the largest crop segment in this industry. Annual bedding plants generated $\$ 1.3$ billion, representing $69 \%$ of the total bedding and garden plant division. Although the wholesale value of bedding and garden plants had decreased $1 \%$ from the previous year, those sold in hanging baskets and containers 5 inches or larger increased, and those sold in smaller containers or flats were reduced compared with the previous year (USDA, 2016).

Considering the economic value of potted bedding plants and the economic and environmental needs to reduce irrigation

Received for publication 4 Dec. 2018. Accepted for publication 8 Mar. 2019.

This project was funded in part by the American Floral Endowment.

${ }^{1}$ Corresponding author. E-mail: tstarman@tamu. edu.
A greenhouse production challenge to growing bedding plants in smaller containers and flats is height control, which typically has been managed by withholding irrigation combined with several plant growth regulator applications to produce compact plants with shorter internodes (Dole and Wilkins, 1999). Reduced irrigation inhibited petunia (Petunia $\times$ hybrida) shoot growth, which implied that lower SMC could be used as an effective growth control method during greenhouse production of petunias (Blanusa et al., 2009; Niu et al., 2006). Water deficits induced by amending the substrate with osmotic compounds produced more compact salvia ( $\mathrm{Sal}$ via splendens 'Bonfire') with greater leaf area:height (Burnett et al., 2005).

Sensor-based irrigation systems are being used to reduce irrigation water usage and produce more compact plants with lower costs while increasing or maintaining their aesthetic quality. The sensor-based irrigation system was first developed by Nemali and van Iersal in 2006 to reduce water consumption by maintaining a distinct and constant SMC (Nemali and van Iersel, 2006). Previous research showed $40 \%$ SMC to be similar to the traditional wellirrigated treatment commonly used by growers for potted plant production, whereas $20 \%$ SMC was an alternative irrigation treatment that reduced water usage without detrimental effects on plant quality (Alem et al., 2015; Bayer et al., 2015; Guo et al., 2018; Jacobson et al., 2015).

Using a sensor-controlled dry-down method, the responses of two bedding plant species to wide-range (WR) SMC (CC dried down to $20 \%$ SMC) varied compared with narrow-range (NR) SMC (CC dried down to $40 \% \mathrm{SMC}$ ). WR-SMC produced more compact angelonia (Angelonia angustifolia 'Angelface Blue'), but it did not impact heliotrope (Heliotropium arborescens 'Simply Scentsational') shoot growth; however, both species had more root growth with WRSMC. WR-SMC increased the visual quality of both angelonia and heliotrope postproduction by increasing the percentage of plant shoots covered with inflorescences and decreased water input during production, thereby decreasing production costs (Guo et al., 2018).

Even though studies have been performed to determine plant responses to water deficits during greenhouse production, the effects of water deficits on postproduction quality remain unclear (Islam and Joyce, 2015). The objective of this study was to ascertain the effects of NR-SMC compared to WR-SMC irrigation methods on growth, development, and physiological parameters during the production of coleus, petunia, lantana, impatiens, and salvia grown in 1.67-L containers. The new trend of growing bedding plant species in larger containers (USDA, 2016), much like potted flowering and foliage plants are produced, was further justification to study irrigation of bedding plants grown in pots rather than flats. roseus) (Burnett and van Iersel, 2008; Garland et al., 2012; Jaleel et al., 2008; Nemali and van Iersel, 2008). 
Table 1. Effect of two substrate moisture contents (SMC): (1) wide range (WR) (54\% to 20\% SMC); and, narrow range (NR) (54\% to 40\% SMC) on shoot dry weight (DW) and root ball coverage percentage on the bottom and side of Solenostemon scutellarioides 'French Quarter', Petunia $\times$ hybrida 'Colorworks Pink Radiance', Lantana camara 'Lucky Flame', and Impatiens $\times$ hybrida 'Sunpatiens Compact Hot Coral' (SCC) in 2017, and of 'Sunpatiens Spreading Lavender' (SSL) and Salvia splendens 'Red Hot Sally II' in 2018.

\begin{tabular}{|c|c|c|c|c|c|c|c|}
\hline \multirow{3}{*}{$\begin{array}{l}\text { SMC\% } \\
\text { WR-SMC }\end{array}$} & \multirow{3}{*}{$\frac{\text { Plant }}{\text { Coleus }}$} & & & \multicolumn{4}{|c|}{ Root ball coverage $(\%)$} \\
\hline & & \multicolumn{2}{|c|}{ Shoot DW } & \multicolumn{2}{|c|}{ Bottom } & \multicolumn{2}{|c|}{ Side } \\
\hline & & 34.6 & $a^{z}$ & 39.7 & $\mathrm{a}$ & 52.5 & $\mathrm{a}$ \\
\hline NR-SMC & & 33 & $\mathrm{a}$ & 40.1 & $\mathrm{a}$ & 50 & $\mathrm{a}$ \\
\hline ANOVA & & NS & & NS & & NS & \\
\hline WR-SMC & Petunia & 11.8 & $\mathrm{~b}$ & 44.3 & $\mathrm{a}$ & 81.8 & a \\
\hline NR-SMC & & 17.8 & $\mathrm{a}$ & 33.4 & $b$ & 76.8 & $\mathrm{a}$ \\
\hline ANOVA & & $* *$ & & $*$ & & NS & \\
\hline WR-SMC & Lantana & 8 & $\mathrm{~b}$ & 30.5 & $\mathrm{a}$ & 49.8 & $\mathrm{a}$ \\
\hline NR-SMC & & 12.6 & $\mathrm{a}$ & 32.3 & $\mathrm{a}$ & 44.8 & $\mathrm{a}$ \\
\hline ANOVA & & $* * *$ & & NS & & NS & \\
\hline WR-SMC & Impatiens SCC & 7.1 & $\mathrm{~b}$ & 21.4 & $\mathrm{a}$ & 60.2 & $\mathrm{a}$ \\
\hline NR-SMC & & 8.5 & $\mathrm{a}$ & 13 & $\mathrm{~b}$ & 56.5 & $\mathrm{a}$ \\
\hline ANOVA & & $* *$ & & $* *$ & & NS & \\
\hline WR-SMC & Impatiens SSL & 12.5 & $\mathrm{a}$ & 63.5 & $\mathrm{~b}$ & 35.8 & $\mathrm{~b}$ \\
\hline NR-SMC & & 13 & $\mathrm{a}$ & 81.1 & $\mathrm{a}$ & 45.1 & $\mathrm{a}$ \\
\hline ANOVA & & NS & & $*$ & & $*$ & \\
\hline WR-SMC & Salvia & 11.7 & $\mathrm{~b}$ & 56.9 & $b$ & 51.9 & $\mathrm{~b}$ \\
\hline NR-SMC & & 16.6 & $\mathrm{a}$ & 75.5 & $\mathrm{a}$ & 68.3 & $\mathrm{a}$ \\
\hline ANOVA & & $* * *$ & & $* *$ & & $* *$ & \\
\hline
\end{tabular}

${ }^{\mathrm{z}}$ Means separated by Student's $t$ test at $P \leq 0.05$.

Ns $, *, * *, * * *$ Nonsignificant or significant at $P \leq 0.05,0.01$, or 0.001 , respectively.

We used the same dry-down method as described previously (Guo et al., 2018) to apply SMC treatments, and we irrigated plants to CC (54\%) after target SMC levels were indicated by sensor readings. The root substrate was allowed to dry down to the target SMC, and it was re-watered to CC repeatedly as needed. We determined whether plants produced with WR-SMC acclimated to infrequent irrigation during simulated shelf life and analyzed the economics of these irrigation methods by considering production inputs and shrinkage through the market channels. Finally, we quantified plant quality before and after simulated shelf life. Our hypothesis was that WR-SMC during production would lower irrigation-associated costs, control growth, better-acclimate plants to the postproduction environment, and allow plants to maintain higher visual quality during postproduction.

\section{Materials and Methods}

Plant material and growing conditions. Rooted cuttings of coleus (Solenostemon scutellarioides) 'French Quarter', petunia (Petunia $\times$ hybrida) 'Colorworks Pink Radiance', lantana (Lantana camara) 'Lucky Flame', and impatiens (Impatiens $\times$ hybrida) 'Sunpatiens Compact Hot Coral' (SCC) grown in 102 liner trays were received and transplanted on 30 Jan. 2017. 'Sunpatiens Spreading Lavender' (SSL) grown in 102 liner trays and salvia (Salvia officinalis) 'Red Hot Sally II' seedlings grown in 128 plug trays with four seedlings per plug were received and transplanted on 15 Mar. 2018. All plants were purchased from Tagawa
Greenhouses, Inc. (Denver, CO), and graded for uniformity on arrival. Each plant was transplanted to a $1.67-\mathrm{L}$ (6.5-inch round) container (The HC Companies, Inc., Middlefield, $\mathrm{OH}$ ) with commercial peat-based soilless root substrate $(85 \% \mathrm{Ca}$ nadian sphagnum peat moss and $15 \%$ perlite; BM 6; Berger, Saint-Modeste, Canada). During the greenhouse production period, a water-soluble fertilizer $(20 \mathrm{~N}-4.4 \mathrm{P}-16.6 \mathrm{~K}$ Peters 20-10-20; Scotts Miracle-Gro Company, Marysville, $\mathrm{OH})$ was applied with each irrigation event, with a nitrogen concentration of $200 \mathrm{mg} \cdot \mathrm{L}^{-1}$. Plants were treated with an etridiazole and thiophanatemethyl (Banrot; Everris NA Inc., Dublin, $\mathrm{OH})$ root substrate drench after transplantation to prevent root rot. Plants were then allowed $14 \mathrm{~d}$ for root establishment before initiation of SMC treatments on 20 Feb. 2017 and 26 Mar. 2018. SMC treatments were continual throughout the production weeks. Electrical conductivity (EC) and $\mathrm{pH}$ readings were obtained weekly using the PourThru method (Wright, 1986) with Laqua Twin EC and $\mathrm{pH}$ meters (Spectrum Technologies Inc., Aurora, IL). No differences were found between SMC treatments for any of the cultivars.

Plants were grown in a glass wall and polycarbonate roof greenhouse in College Station, TX, for two experiments from 30 Jan. to 5 May 2017 and from 15 Mar. to 18 May 2018. Environmental data were measured at the plant canopy level by WatchDog 450 data loggers and LightScout quantum light sensors (Spectrum Technologies Inc., Aurora, IL). The average temperatures and light intensities in the greenhouse during the experiment were $22.8^{\circ} \mathrm{C}$ day $/ 18.4{ }^{\circ} \mathrm{C}$ night in

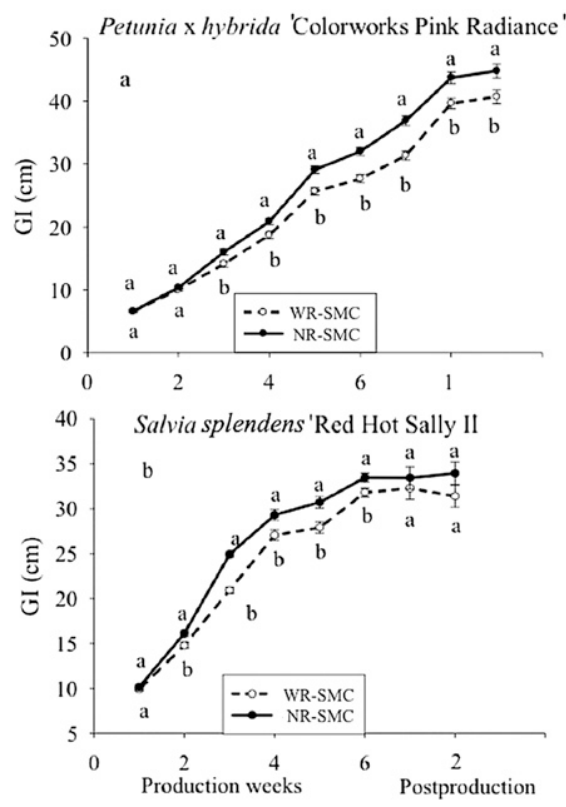

Fig. 1. Effects of two substrate moisture contents (SMC): (1) wide-range SMC (WR-SMC; 54\% to $20 \% \mathrm{SMC}$ ) and (2) narrow-range SMC (NRSMC; $54 \%$ to $40 \%$ SMC) according to the weekly growth index (GI; GI = plant height/ $2+$ (plant width $1+$ plant width 2 )/4) during production weeks 1 to 8 and 2 weeks of postproduction of (a) Petunia $\times$ hybrida 'Colorworks Pink Radiance' in 2017, and during production weeks 1 to 6 and 2 weeks of postproduction of (b) salvia splendens 'Red Hot Sally II' in 2018. $\mathrm{SMC}$ was calculated as $\mathrm{SMC}=($ substrate wet weight - substrate dry weight $) \times 100 \% / 1000$.

2017 and $24.5^{\circ} \mathrm{C}$ day $/ 18.4{ }^{\circ} \mathrm{C}$ night in 2018 . During production, the average daily light integral (DLI) and relative humidity were 
$14.6 \mathrm{~mol} \cdot \mathrm{m}^{-2} \cdot \mathrm{d}^{-1}$ and $64.8 \%$ in 2017 and 16.5 $\mathrm{mol} \cdot \mathrm{m}^{-2} \cdot \mathrm{d}^{-1}$ and $54.8 \%$ in 2018 .

In 2017, plants were deemed marketable after 7 weeks of production ( 7 Apr.) for coleus, 8 weeks (14 Apr.) for petunia, and 9 weeks (21 Apr.) for lantana and impatiens SCC. At that time, plants were subjected to a simulated shipping process consisting of hand-watering to $\mathrm{CC}$ before moving plants by cart to a dark laboratory for $48 \mathrm{~h}$ at $22.4{ }^{\circ} \mathrm{C}$ and $42.4 \%$ relative humidity. In 2018, impatiens SSL and salvia were deemed marketable after 6 weeks of production (3 May). Then, they went through a simulated shipping

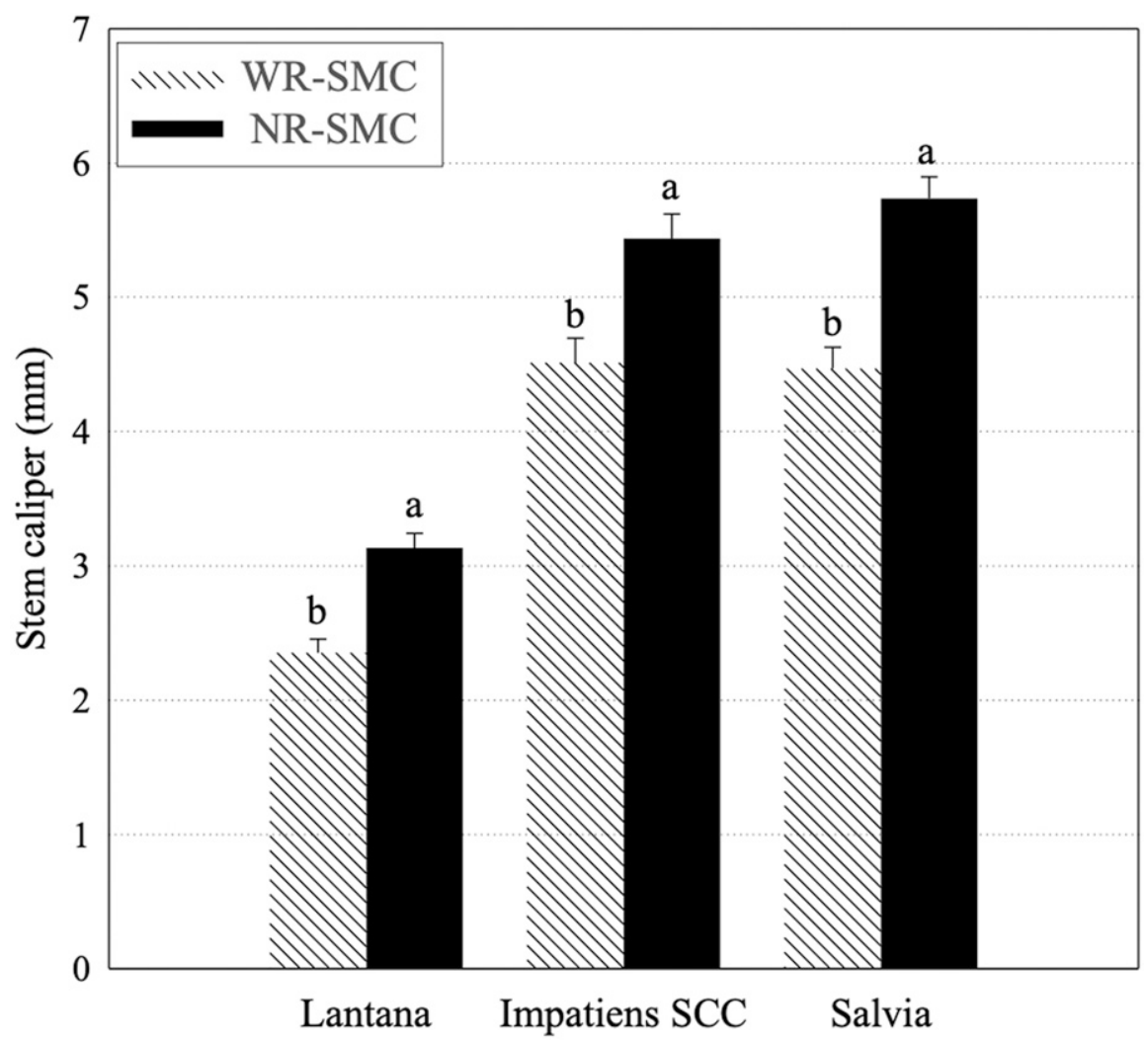

Fig. 2. Effects of two substrate moisture contents (SMC): (1) wide-range SMC (WR-SMC; $54 \%$ to $20 \%$ SMC) and (2) narrow-range SMC (NR-SMC; $54 \%$ to $40 \%$ SMC) on the stem caliper at the end of production of Lantana camara 'Lucky Flame' and Impatiens xhybrida 'Sunpatiens Compact Hot Coral' (SCC) in 2017, and of Salvia splendens 'Red Hot Sally II' in 2018. SMC was calculated as SMC $=($ substrate wet weight - substrate dry weight $) \times 100 \% / 1000$. day $/ 20.0{ }^{\circ} \mathrm{C}$ night, $8.5 \mathrm{~mol} \cdot \mathrm{m}^{-2} \cdot \mathrm{d}^{-1}$, and $52.3 \%$ in 2018 .

SMC treatment. One of two irrigation treatments, WR-SMC or NR-SMC, was applied during six experiments (one cultivar per experiment) during the production weeks. NRSMC consisted of allowing the substrate to dry down to $40 \%$ SMC before hand-watering to CC (54\% SMC), which was until the initiation of drainage. WR-SMC consisted of allowing substrate to dry down to $20 \%$ SMC before hand-watering to CC. SMC was defined as the percentage of $\mathrm{V}_{\mathrm{w}} / \mathrm{V}_{\mathrm{T}}\left(\mathrm{V}_{\mathrm{w}}\right.$ is the volume of water and $\mathrm{V}_{\mathrm{T}}$ is the total volume of substrate particles, water, and air space). SMC was monitored by a watchdog 1000 series Micro Station and SM 100 WaterScout soil moisture sensors (Spectrum Technologies, Inc., Aurora, IL). There was one sensor per treatment per cultivar inserted in the root substrate of a container that was closer to the center of the greenhouse bench to reflect the average SMC of the treatment and to avoid the drying effect of the bench edges. Sensors recorded SMC every $30 \mathrm{~min}$, and each irrigation event was determined based on the sensor readings (observed daily) and the calibration of the sensor.

Sensor calibration. Soil moisture sensors were calibrated by filling five 1-L plastic beakers with a 1-L volume of oven-dried root substrate. Substrate density was standardized by tapping dry substrate-filled plastic beakers five times from a uniform height of $\approx 3$ to $6 \mathrm{~cm}$ above a sturdy table (Fonteno et al., 1995). Each beaker was emptied in one of five polyethylene plastic bags (Ziploc; S.C. Johnson \& Son, Inc., Racine, WI), and 100, $200,300,400$, or $500 \mathrm{~mL}$ of water was poured in one of the five bags. Root substrate was thoroughly mixed with the water and allowed to incubate for $24 \mathrm{~h}$. All dry weight (DW), wet weight (WW), and the net weight of the beakers were measured and recorded. Root substrate was repacked into the same plastic beaker as previously described. Three sensor readings were performed at three different locations in the beaker to avoid performing readings too close to the edge of the beaker (according to the WaterScout SM 100 Soil Moisture Sensor Product Manual). SMC was calculated as $\mathrm{SMC}=(\mathrm{WW}-\mathrm{DW}) \times 100 \% /$ 1000 (Cai et al., 2012).

Table 2. Effect of two substrate moisture contents (SMC): (1) wide range (WR) ( $54 \%$ to $20 \%$ SMC); and, narrow range (NR) ( $54 \%$ to $40 \%$ SMC) on bud, flower, and senesced flower number of Petunia $\times$ hybrida 'Colorworks Pink Radiance' from production weeks 5 to 7 and 2 weeks postproduction in 2017.

\begin{tabular}{|c|c|c|c|c|c|c|c|c|c|c|}
\hline \multirow{2}{*}{ Bud number } & \multicolumn{6}{|c|}{ Production } & \multicolumn{4}{|c|}{ Postproduction } \\
\hline & \multicolumn{2}{|c|}{ Wk 5} & \multicolumn{2}{|c|}{ Wk 6} & \multicolumn{2}{|c|}{ Wk 7} & \multicolumn{2}{|c|}{ Wk 1} & \multicolumn{2}{|c|}{ Wk 2} \\
\hline WR-SMC & 19.4 & $a^{z}$ & 17.3 & $\mathrm{~b}$ & 17.3 & $\mathrm{~b}$ & 14.7 & $\mathrm{a}$ & 15.4 & $\mathrm{a}$ \\
\hline \multicolumn{11}{|c|}{ Flower number } \\
\hline WR-SMC & 18.3 & $\mathrm{~b}$ & 21.0 & $\mathrm{~b}$ & 29.8 & $\mathrm{~b}$ & 22.1 & $\mathrm{~b}$ & 32.6 & $\mathrm{a}$ \\
\hline NR-SMC & 24.7 & $\mathrm{a}$ & 24.5 & $\mathrm{a}$ & 37.4 & $\mathrm{a}$ & 33.0 & $\mathrm{a}$ & 23.4 & $\mathrm{~b}$ \\
\hline WR-SMC & 1.9 & $\mathrm{a}$ & 13.2 & $\mathrm{a}$ & 26.1 & $\mathrm{a}$ & 29.6 & $\mathrm{~b}$ & 49.4 & $\mathrm{~b}$ \\
\hline NR-SMC & 1.5 & $\mathrm{a}$ & 14.6 & a & 31.3 & $\mathrm{a}$ & 52.8 & $\mathrm{a}$ & 89.9 & $\mathrm{a}$ \\
\hline ANOVA & NS & & NS & & NS & & $* * *$ & & $* * *$ & \\
\hline
\end{tabular}

${ }^{\mathrm{z}}$ Means separation by student $t$ test at $P \leq 0.05$.

Ns, *,**,**Nonsignificant or significant at $P \leq 0.05,0.01$, or 0.001 , respectively. 
Data collection. To perform an economic analysis of water usage, containers were weighed before each irrigation event during the production and postproduction stages of the experiments. After irrigation, containers were allowed to drain for $1 \mathrm{~h}$ and then reweighed. The weight difference was calculated and recorded to determine the total irrigation volume. Each irrigation event was documented and summed to determine the

Table 3. Effect of two substrate moisture contents (SMC): (1) wide range (WR) $(54 \%$ to $20 \%$ SMC); and, narrow range (NR) (54\% to $40 \%$ $\mathrm{SMC}$ ) on bud and flower number of Lantana camara 'Lucky Flame' and bud number of Impatiens $\times$ hybrida 'Sunpatiens Compact Hot Coral' (SCC) during 2 weeks of postproduction in 2017.

\begin{tabular}{lcccc}
\hline & \multicolumn{3}{c}{ Postproduction } \\
\cline { 2 - 5 } & \multicolumn{3}{c}{ Wk 1 } & Wk 2 \\
\hline Lantana bud number & & & & \\
WR-SMC & 15.1 & $\mathrm{~b}^{\mathrm{z}}$ & 7.3 & $\mathrm{~b}$ \\
NR-SMC & 26.5 & $\mathrm{a}$ & 15.6 & $\mathrm{a}$ \\
ANOVA & $* *$ & & $* * *$ & \\
Lantana inflorescence number & & & \\
WR-SMC & 7.3 & $\mathrm{a}$ & 6.7 & $\mathrm{~b}$ \\
NR-SMC & 7.9 & $\mathrm{a}$ & 13.7 & $\mathrm{a}$ \\
ANOVA & NS & & $* *$ & \\
Impatiens SCC bud number & & & \\
WR-SMC & 38.2 & $\mathrm{~b}$ & 37.4 & $\mathrm{~b}$ \\
NR-SMC & 52.1 & $\mathrm{a}$ & 47.2 & $\mathrm{a}$ \\
ANOVA & $* * *$ & & $*$ & \\
\hline
\end{tabular}

${ }^{\mathrm{z}}$ Means separation by student $t$ test at $P \leq 0.05$. Ns, $*, * *, * * *$ Nonsignificant or significant at $P \leq$ $0.05,0.01$, or 0.001 , respectively. total number of irrigation events during production and/or postproduction.

Plant height and width were recorded weekly starting at production week 1 for all six different cultivars. Plant height was measured from the root substrate surface to the tallest point of the plant. Two plant widths were measured across the greatest plant width and the perpendicular width. The growth index (GI) was calculated as: GI = plant height $/ 2+$ (plant width $1+$ plant width2)/4 (Niu et al., 2007). At the end of production, the stem caliper was measured under the node of the third fully expanded leaf with a digital caliper on all six cultivars. The stem calipers on petunia, lantana, impatiens SCC, impatiens SSL, and salvia were collected at the end of postproduction. Leaf thickness between two major leaf veins was measured on a young, fully unfolded leaf with a digital caliper at the end of production and postproduction for all six cultivars. The bud, flower, and senesced flower number were measured weekly on petunia, lantana, and impatiens SCC. The same data were collected for impatiens SSL and salvia only at the end of production and postproduction.

Instantaneous leaf gas exchange parameters [net carbon assimilation rate $\left(\mathrm{P}_{\mathrm{n}}\right)$, stomatal conductance $\left(g_{\mathrm{S}}\right)$, and transpiration rate (E)] and the relative greenness of leaves (SPAD-502; Minolta Camera Co., Osaka, Japan) were measured weekly starting at week 4 or 5 until the end of production for all cultivars except for coleus due to its characteristic multicolored, patterned leaves. A young, fully expanded leaf was put in the leaf chamber (cuvette) of a portable photosynthesis system (LI-6400XT; LI-COR Inc., Lincoln, NE) between 1000 and $1200 \mathrm{HR}$, with the cuvette conditions set at $25{ }^{\circ} \mathrm{C}, 1200$ $\mu \mathrm{mol} \cdot \mathrm{m}^{-1} \cdot \mathrm{s}^{-1}$, and $400 \mu \mathrm{mol} \mathrm{CO}_{2}$. Coleus, lantana, petunia, and salvia midday water potential measurements were performed weekly with a pressure bomb (Soil Moisture Equipment Corp., Santa Barbara, CA) starting at week 5. At the end of postproduction, all cultivars were destructively harvested and total plant shoot DW was determined after being oven-dried at $80^{\circ} \mathrm{C}$ for $48 \mathrm{~h}$ to constant weights.

To measure salvia quality, five replications were dissected at the end of production, and five were dissected at the end of postproduction. Data collected on the main stems of the four salvia seedlings per plug were averaged to determine the total stem height, vegetative stem segment with leaves or abscised leaves, inflorescence segment with fresh flowers or abscised flowers, immature, flowering, and senesced inflorescence numbers, and chlorotic leaf number.

Photos of shoots were obtained at the end of production and postproduction to determine the shoot coloring percentage (the percentage of the plant canopy covered by flowers) for all cultivars except coleus and salvia due to their lack of inflorescences and vertical inflorescences, respectively. To determine how SMC affected root orientation in the container, root ball photos were obtained
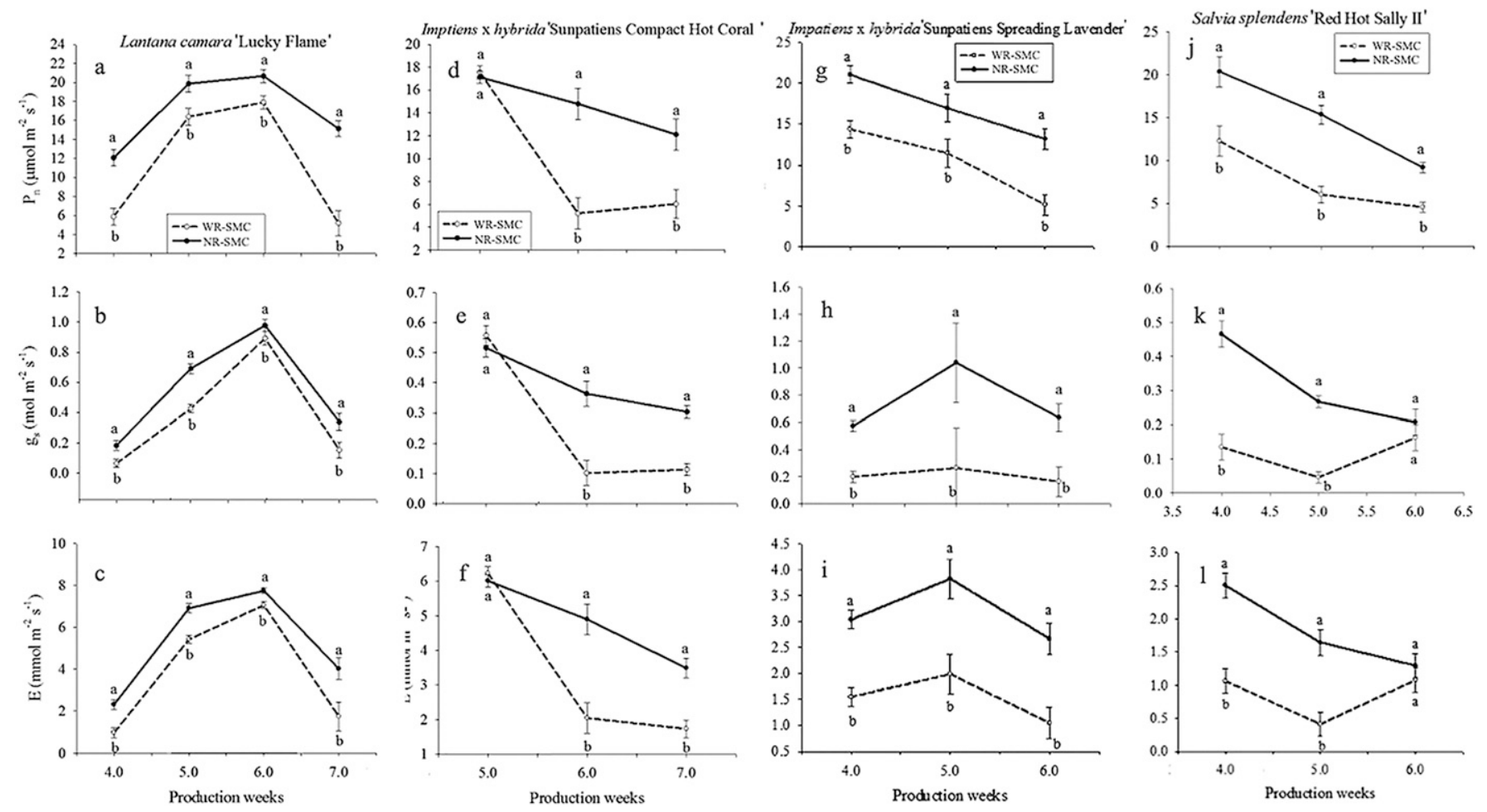

Fig. 3. Effects of two substrate moisture contents (SMC): (1) wide-range SMC (WR-SMC; $54 \%$ to $20 \%$ SMC) and (2) narrow-range SMC (NR-SMC; $54 \%$ to $40 \%$ $\mathrm{SMC}$ ) on the leaf net photosynthetic rate (Pn), stomatal conductance $\left(g_{\mathrm{S}}\right)$, and transpiration rate (E) from production weeks 4 to 7 of Lantana camara 'Lucky Flame' and Impatiens $\times$ hybrida 'Sunpatiens Compact Hot Coral' in 2017, and of 'Sunpatiens Spreading Lavender' and Salvia splendens 'Red Hot Sally II' in 2018. Means were separated within the group by Student's $t$ test at $P \leq 0.05$. Means with the same letter are not different. SMC was calculated as SMC $=$ (substrate wet weight - substrate dry weight) $\times 100 \% / 1000$. 
at the end of postproduction from the bottom of the root ball and both sides of the root ball. The root ball covering percentage was the percentage of the substrate surface covered by roots after removal from the container. The shoot coloring percentage and root ball coverage percentage were analyzed with Photoshop CS6 (Adobe Systems Inc., San Jose, CA). Photoshop quantified the colored area (flowers) and green area (leaves), and the total shoot area was calculated as the colored area plus the green area. The shoot coloring percentage was then calculated as the colored area divided by the total shoot area. To determine the root ball coverage percentage, Photoshop quantified the total root ball area as the root area plus the substrate area. The root ball coverage percentage was calculated as the root coverage area divided by the total area.

Experimental design and data analysis. The experiment had a randomized complete design and involved two treatments (WRSMC and NR-SMC) with 15 replications in 2017 and 10 replications in 2018. Each cultivar was analyzed separately. A oneway analysis of variance (ANOVA) procedure was used to test the effects of SMC treatments on plant growth. Data were analyzed by JMP (SAS Institute, Cary, NC). Mean separation was conducted using Student $t$ tests if the significance level was $5 \%$.

\section{Results and Discussion}

Plant morphology. Coleus and impatiens SSL GI (data not shown; coleus: $32.4 \mathrm{~cm}$, $\mathrm{SD}=6.6 \mathrm{~cm}$; impatiens SSL: $31.6 \mathrm{~cm}, \mathrm{SD}=0.9$ $\mathrm{cm}$ ) and shoot DW were unaffected by SMC treatment (Table 1). The GI of petunia and salvia were greater with NR-SMC 1 or 2 weeks after SMC treatments began, and growth continued throughout the production weeks (Fig. 1). The petunia GI continued to be greater, whereas that of salvia was the same with both treatments during postproduction (Fig. 1). Petunia, lantana, impatiens SCC, and salvia had higher shoot DW with NR-SMC (Table 1), although there were no differences in the GI based on SMC for lantana (data not shown; $34.2 \mathrm{~cm}, \mathrm{SD}=2.2$ $\mathrm{cm}$ ) and impatiens SCC (data not shown; 26.6 $\mathrm{cm}, \mathrm{SD}=0.6 \mathrm{~cm})$.

The root ball coverage percentage varied with cultivars. Coleus and lantana root coverage percentages were unaffected by SMC (Table 1). Petunia and impatiens SCC with WR-SMC had more roots at the bottom of the container, but not at the sides of the container (Table 1). Impatiens SSL and salvia had higher root ball coverage at the bottom and sides of the container with NR-SMC (Table 1). WR-SMC reduced the stem caliper of lantana, impatiens SCC, and salvia (Fig. 2).

The level of adaptation was highly dependent on species and cultivar drought tolerance. Impatiens SCC is a hybrid, drought-tolerant, compact plant with a root system adapted to full sun or part shade (Dole and Wilkins, 1999; Sakata Seed America,
2017; Sato and Minemura, 2014). This could explain why impatiens SCC with WR-SMC produced more roots without affecting shoot GI. In contrast to impatiens SCC, impatiens SSL was bred to have a spreading habit (Sato and Minemura, 2016). In our present study, impatiens SSL shoot DW, GI, and stem caliper were unaffected by SMC treatments, and only root growth was inhibited with WRSMC. This indicated that by repeatedly drying down to $20 \% \mathrm{SMC}$, impatiens SSL redirected more energy to support shoot growth and flowering than root development. Coleus has a high water-use requirement and was irrigated more than the other cultivars. This trait minimized the difference between irrigation amount and frequency between WR-SMC and NR-SMC (Table 6) compared with the other cultivars tested; therefore, coleus morphological variables were unaffected.

A water deficit during production has been shown to cause shoot growth inhibition, including reduced leaf surface area, plant height, and shoot DW. Previous studies reported that petunia, salvia, and lantana shoot DW decreased as the SMC level decreased (Alem et al., 2015; Eakes et al., 1991; Kim and van Iersel, 2009). Lower SMC inhibited the shoot growth of other bedding plant species, including vinca, carnation ( $\mathrm{Di}$ anthus caryophyllus), angelonia, American alumroot, and gaura (Alem et al., 2015; Burnett and van Iersel, 2008; Garland et al., 2012; Guo et al., 2018; Jacobson et al., 2015; Jaleel et al., 2008; Kim and van Iersel, 2009).

In an environment with a water deficit, root growth is favored over shoot growth (Taiz et al., 2015). This was considered beneficial for adaptation and surviving a water stress situation (Blum, 1996). Angelonia, heliotrope, carnation, crimson bottlebrush (Callistemon citrinus), geranium (Pelargonium $\times$ hortorum), impatiens, and oleander (Nerium oleander) were reported to have a higher root density or root-to-shoot ratio with lower SMC (Álvarez et al., 2009, 2011, 2013; Álvarez and Sánchez-Blanco, 2013; Chyliński et al., 2007; Guo et al., 2018; Niu et al., 2008; Sánchez-Blanco et al., 2009).

Petunia grown in NR-SMC had higher flower and bud numbers 6 and 7 weeks after SMC treatments began. However, petunia grown in NR-SMC had higher senesced flower numbers; therefore, it had lower flower and bud numbers during postproduction (Table 2). Lantana and impatiens SCC bud, flower, and senesced flower numbers were unaffected by SMC treatments at the end of production (data not shown), with averages of $13.8(\mathrm{SD}=1.4), 0.1(\mathrm{SD}=0.1)$, and 0 for lantana and $46.6(\mathrm{SD}=2.0), 5.8(\mathrm{SD}=$ $0.8)$, and $3.1(\mathrm{SD}=0.5)$ for impatiens $\mathrm{SCC}$, respectively. At the end of postproduction, lantana with NR-SMC had greater bud and inflorescence numbers because plants with NR-SMC produced more buds at the end of production (Table 3). During postproduction, the impatiens SCC bud number was greater with NR-SMC (Table 3), but the flower number was unaffected by SMC (data not shown), with averages of $4.1(\mathrm{SD}=1.1)$ during the first week and $16.0(\mathrm{SD}=1.8)$ during the second week. Impatiens SSL flower and bud numbers were not different based on SMC treatments during production and postproduction (data not shown), with averages of $5.3(\mathrm{SD}=1.0)$ and $44.0(\mathrm{SD}=2.3)$ for production and $18.2(\mathrm{SD}=2.2)$ and $46.9(\mathrm{SD}=4.1)$ for postproduction.

During flowering, plants are more susceptible to water stress. Research has indicated that, with a water deficit, root growth in deeper soil required allocation of photosynthetic products to root tips. However, during flowering, root growth is less pronounced
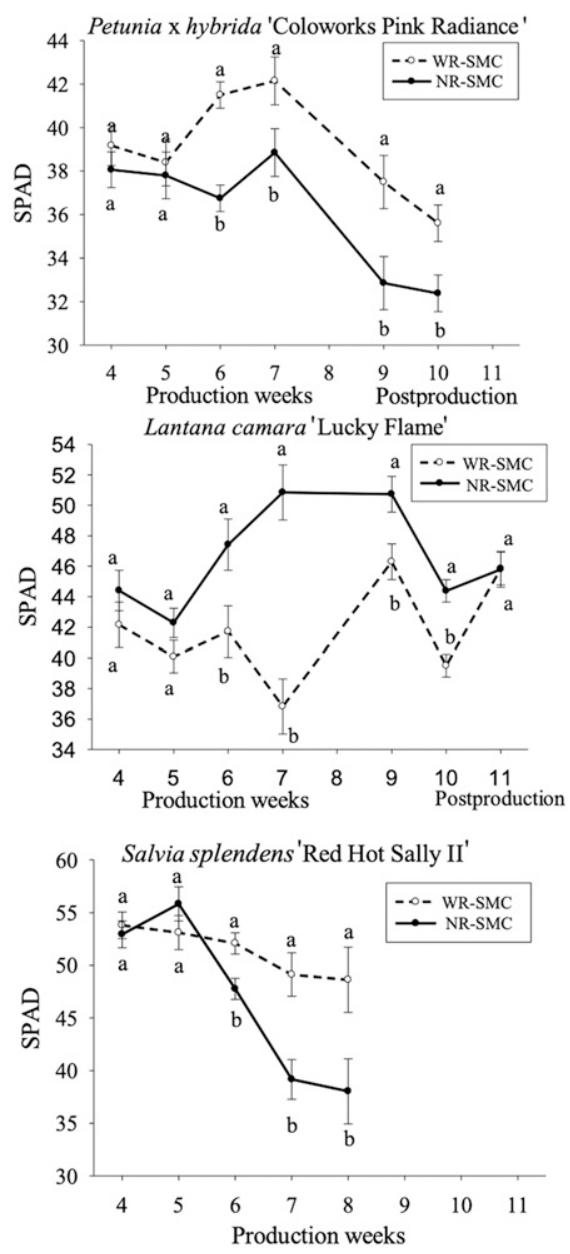

Fig. 4. Effects of two substrate moisture contents (SMC): (1) wide-range SMC (WR-SMC; 54\% to $20 \% \mathrm{SMC}$ ) and (2) narrow-range SMC (NR-SMC; $54 \%$ to $40 \% \mathrm{SMC}$ ) on the leaf chlorophyll index [Special Products Analysis Division (SPAD) values] for (a) Petunia $\times$ hybrida 'Colorworks Pink Radiance' and (b) Lantana camara 'Lucky Flame' during production weeks 4 to 9 and 2 weeks of postproduction in 2017, and for (c) Salvia splendens 'Red Hot Sally II' during production weeks 4 to 6 and 2 weeks of postproduction in 2018. Means were separated by Student's $t$ test multiple comparisons at $P \leq 0.05$. Means with the same letter are not different. SMC was calculated as $\mathrm{SMC}=($ substrate wet weight substrate dry weight $) \times 100 \% / 1000$. 

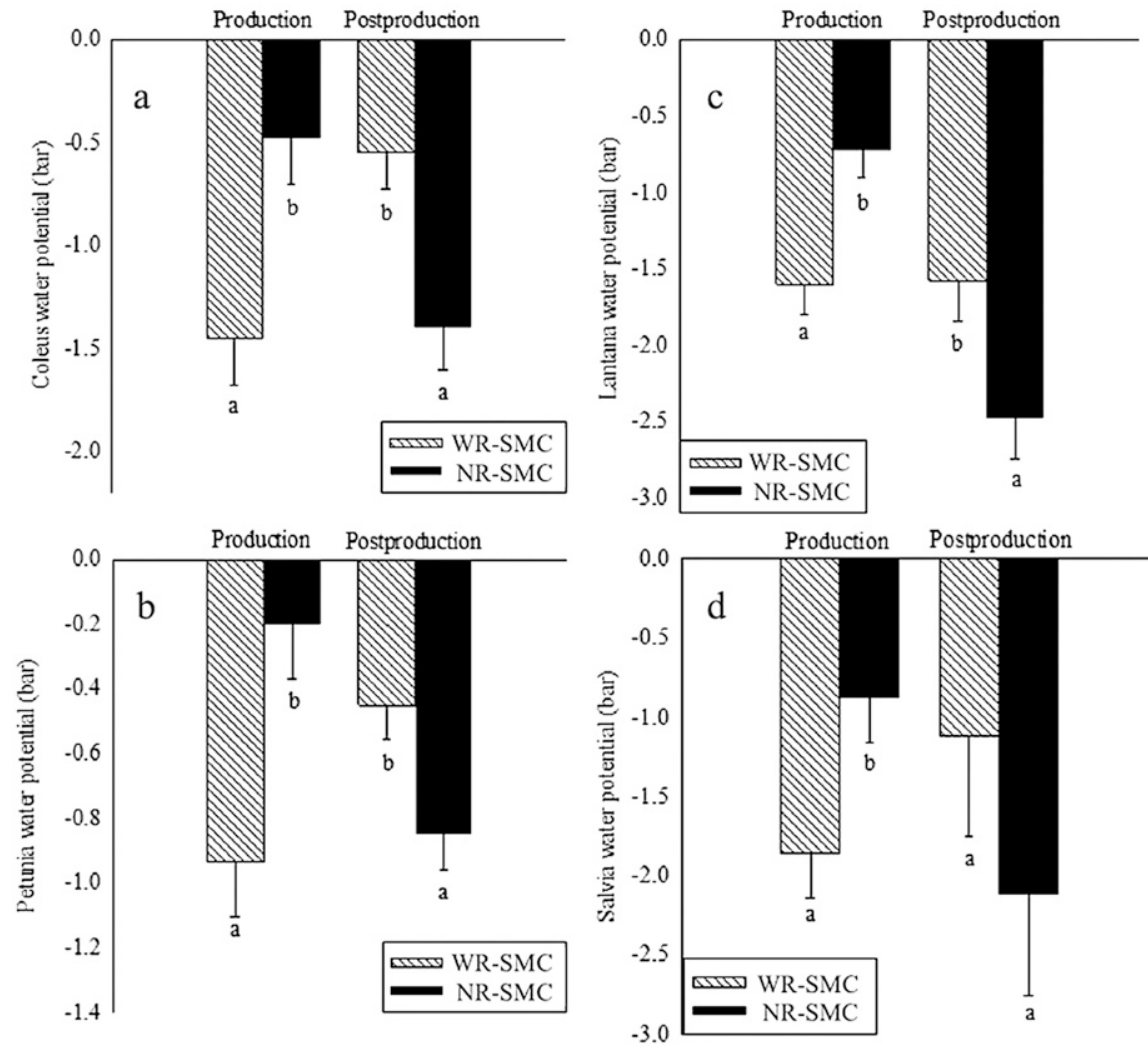

Posproduction

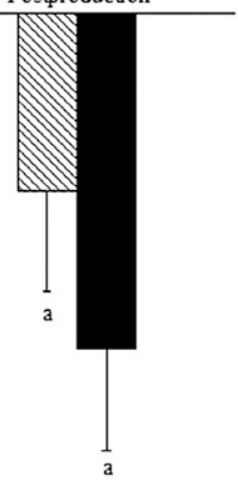

Fig. 5. Effects of two substrate moisture contents (SMC): (1) wide-range SMC (WR-SMC; $54 \%$ to $20 \%$ SMC) and (2) narrow-range SMC (NR-SMC; $54 \%$ to $40 \%$ SMC) on midday water potential of (a) coleus (Solenostemon scutellarioides) 'French Quarter', (b) petunia (Petunia $\times$ hybrida) 'Colorworks Pink Radiance', and (c) lantana (Lantana camara) 'Lucky Flame' in 2017, and of (d) salvia (Salvia splendens) 'Red Hot Sally II' in 2018 during production weeks and postproduction weeks. Means were separated by Student's $t$ test multiple comparisons at $P \leq 0.05$. Means with the same letter are not different. $\mathrm{SMC}$ was calculated as $\mathrm{SMC}=($ substrate wet weight - substrate dry weight $) \times 100 \% / 1000$.

Table 4. Effect of two substrate moisture contents (SMC): (1) wide range (WR) $(54 \%$ to $20 \%$ $\mathrm{SMC})$; and, narrow range (NR) (54\% to $40 \%$ $\mathrm{SMC}$ ) on shoot coloring percentage at the end of production and the end of postproduction of Petunia $\times$ hybrida 'Colorworks Pink Radiance', Lantana camara 'Lucky Flame', and Impatiens xhybrida 'Sunpatiens Compact Hot Coral' (SCC) in 2017, and of 'Sunpatiens Spreading Lavender' (SSL) in 2018.

\begin{tabular}{|c|c|c|c|c|}
\hline & \multicolumn{4}{|c|}{ Shoot color $(\%)$} \\
\hline & \multicolumn{2}{|c|}{ Production } & \multicolumn{2}{|c|}{ Postproduction } \\
\hline \multicolumn{5}{|l|}{$\overline{\text { Petunia }}$} \\
\hline WR-SMC & 35.7 & $a^{z}$ & 25.5 & $\mathrm{a}$ \\
\hline NR-SMC & 36.7 & $\mathrm{a}$ & 17.5 & $\mathrm{~b}$ \\
\hline ANOVA & \multicolumn{2}{|c|}{ NS } & \multicolumn{2}{|c|}{ ** } \\
\hline \multicolumn{5}{|l|}{ Lantana } \\
\hline WR-SMC & 8.9 & $\mathrm{a}$ & 3.7 & $\mathrm{~b}$ \\
\hline NR-SMC & 7.3 & $\mathrm{a}$ & 9.2 & $\mathrm{a}$ \\
\hline ANOVA & \multicolumn{2}{|c|}{ NS } & \multicolumn{2}{|c|}{ * } \\
\hline \multicolumn{5}{|l|}{ Impatiens SCC } \\
\hline WR-SMC & 5.8 & $\mathrm{~b}$ & 31.4 & $\mathrm{~b}$ \\
\hline NR-SMC & 17.1 & $\mathrm{a}$ & 44.3 & $\mathrm{a}$ \\
\hline ANOVA & \multicolumn{2}{|c|}{$* *$} & \multicolumn{2}{|c|}{$*$} \\
\hline \multicolumn{5}{|l|}{ Impatiens SSL } \\
\hline WR-SMC & 11.3 & $\mathrm{a}$ & 19.8 & $\mathrm{a}$ \\
\hline NR-SMC & 11.2 & $\mathrm{a}$ & 25.2 & $\mathrm{a}$ \\
\hline ANOVA & \multicolumn{2}{|c|}{ NS } & \multicolumn{2}{|c|}{ NS } \\
\hline
\end{tabular}

${ }^{\mathrm{z}}$ Means separation by student $t$ test at $P \leq 0.05$. Ns $, *, * *$, Nonsignificant or significant at $P \leq 0.05$ or 0.01 , respectively. than it is in the vegetative stage due to energy being redirected to the reproductive organs (Taiz et al., 2015). Previous research also indicated that higher SMC combined with more fertilization increased petunia shoot growth and reduced flowering (Alem et al., 2015). Therefore, when there is a water deficit during postproduction, the competition for photosynthetic products between the root and flower could cause more flower senescence in petunia with NR-SMC, as observed in our presented research. However, impatiens SCC and SSL flowers were less affected by the SMC treatments used in this experiment. Even though our research reported that impatiens SCC with NR-SMC had more buds, the flower number was not different with different SMC treatments. Impatiens $\times$ hybrida is a hybrid of Impatiens walleriana and Impatiens hawkeri that has better drought tolerance than Impatiens walleriana. Impatiens walleriana is more sensitive to drought, and it has been reported to have reduced plant height and flower number under water deficit conditions (Sato and Minemura, 2014, 2016; Wegley, 2007).

Plant physiology. During greenhouse production, plant leaf gas exchange, soil-plant analyses development (SPAD) reading, and midday water potential varied among cultivars. Petunia $\mathrm{P}_{\mathrm{n}}, \mathrm{E}$, and $g_{\mathrm{S}}$ were unaffected by

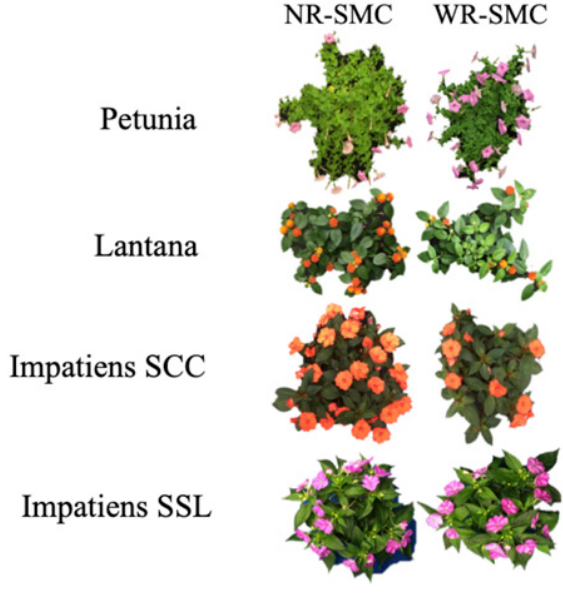

Fig. 6. Photographs of the effects of two substrate moisture contents (SMC): (1) wide-range SMC (WR-SMC; $54 \%$ to $20 \%$ SMC) and (2) narrowrange SMC (NR-SMC; $54 \%$ to $40 \%$ SMC) on shoot coloring percentage for Petunia $\times$ hybrida 'Colorworks Pink Radiance', Lantana camara 'Lucky Flame', Impatiens Xhybrida 'Sunpatiens Compact Hot Coral', and Sunpatiens Spread 'Lavender' at the end of postproduction in 2017 or 2018. SMC was calculated as SMC = (substrate wet weight - substrate dry weight $) \times$ $100 \%$ / 1000 .

SMC (data not shown). Lantana, impatiens SCC and SSL, and salvia had greater $\mathrm{P}_{\mathrm{n}}, \mathrm{E}$, and $g_{\mathrm{S}}$ with NR-SMC (Fig. 3).

Plants respond to water deficits by progressively closing the stomata to reduce evaporation water loss, thereby reducing $\mathrm{P}_{n}$, $g_{\mathrm{S}}$, and E (Tezara et al., 1999). Studies have shown that the carnation, crimson bottlebrush, salvia, rose (Rosa spp.), and geranium leaf gas exchange rates decreased as the SMC level decreased (Álvarez et al., 2009, 2011; Álvarez and Sánchez-Blanco, 2013; Cai et al., 2012, 2014; Eakes et al., 1991; Sánchez-Blanco et al., 2009). In our study, lower photosynthesis rates with WR-SMC for lantana, impatiens SCC and SSL, and salvia led to reductions in their shoot and/or root growth. Even though other studies have shown that the petunia gas exchange rate decreased as the SMC level decreased, this discrepancy from our results could be due to the experimental methods or the lower SMC levels used in other studies $(10 \%$ and/or lower SMC) (Kim et al., 2012; Nemali and van Iersel, 2008; Niu et al., 2006). With a water deficit, before the photosynthetic activity is affected, shoot inhibition can occur to redirect energy to support further root growth in some species (Boyer, 1970; Taiz et al., 2015). Our results for the leaf gas exchange indicated that WR-SMC inhibited petunia shoot growth without affecting its photosynthetic activity and stimulated petunia to have more root growth.

The leaf chlorophyll index quantified by the SPAD reading showed no difference between SMC treatments for the two impatiens cultivars (data not shown). Petunia and salvia with WR-SMC had higher SPAD readings, but lantana with WR-SMC had 
Table 5. Effect of two substrate moisture contents (SMC): (1) wide range (WR) (54\% to 20\% SMC); and, narrow range (NR) (54\% to 40\% SMC) on total stem height, vegetative stem segment with leaves or abscised leaves, inflorescence segment with fresh flowers or abscised flowers, immature, flowering, and senesced inflorescence number and chlorotic leaf number at the end of production and postproduction of Salvia splendens 'Red Hot Sally II' in 2018.

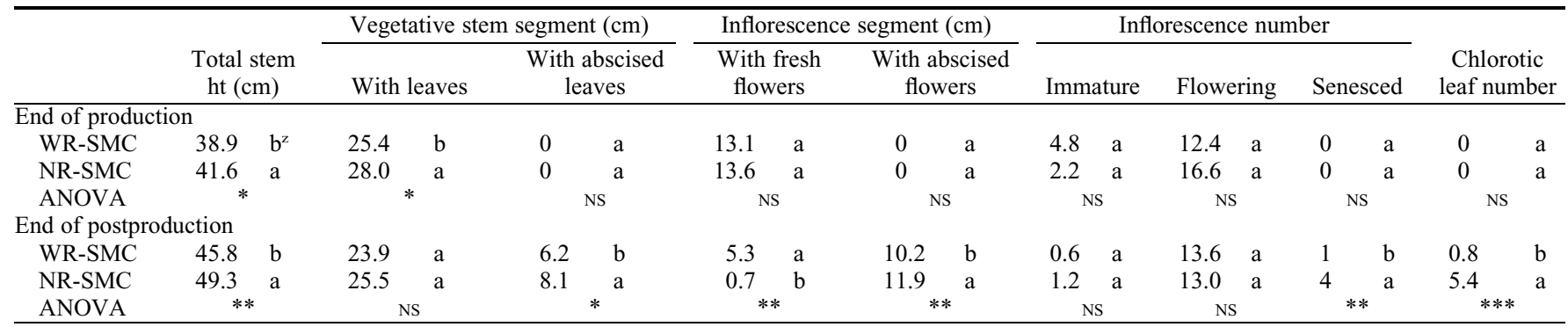

${ }^{\mathrm{z}}$ Means separation by student $t$ test at $P \leq 0.05$.

Ns $* * *, * * *$ Nonsignificant or significant at $P \leq 0.05,0.01$, or 0.001 , respectively.

Table 6. Production irrigation and associated economic implications of Solenostemon scutellarioides 'French Quarter', Petunia $\times$ hybrida 'Colorworks Pink Radiance', Lantana camara 'Lucky Flame', and Impatiens $\times$ hybrida 'Sunpatiens Compact Hot Coral' (SCC) in 2017; 'Sunpatiens Spreading Lavender' (SSL) and Salvia splendens 'Red Hot Sally II' in 2018, grown at one of two substrate moisture contents (SMC): (1) wide range (WR) (54\% to 20\% SMC); and, narrow range (NR) (54\% to $40 \%$ SMC) during 8 weeks of greenhouse production.

\begin{tabular}{|c|c|c|c|c|c|c|c|c|}
\hline \multirow{2}{*}{ Coleus } & \multirow[t]{2}{*}{$\begin{array}{l}\text { Estimated pot } \\
\text { number/bench }\end{array}$} & \multirow[t]{2}{*}{ Space saved $(\%)$} & \multicolumn{2}{|c|}{$\begin{array}{l}\text { Total no. of } \\
\text { irrigation events }\end{array}$} & \multirow[t]{2}{*}{ Labor saved (\%) } & \multicolumn{2}{|c|}{$\begin{array}{c}\text { Irrigation } \\
\text { amount (L/pot) }\end{array}$} & \multirow[t]{2}{*}{$\begin{array}{c}\text { Irrigation } \\
\text { amount saved }(\%)\end{array}$} \\
\hline & & & & & & & & \\
\hline WR-SMC & $41.0^{\mathrm{z}}$ & $7.8^{y}$ & $11^{\mathrm{x}}$ & $b^{w}$ & $8.3^{v}$ & $5.6^{\mathrm{u}}$ & $\mathrm{a}$ & $-0.3^{\mathrm{t}}$ \\
\hline NR-SMC & 38.0 & 0.0 & 12 & $\mathrm{a}$ & 0.0 & 5.5 & $\mathrm{a}$ & 0.0 \\
\hline \multicolumn{9}{|l|}{ Petunia } \\
\hline WR-SMC & 51.0 & 24.1 & 8 & $\mathrm{~b}$ & 27.3 & 3.6 & $\mathrm{a}$ & 8.1 \\
\hline NR-SMC & 39.0 & 0.0 & 11 & $\mathrm{a}$ & 0.0 & 3.9 & $\mathrm{a}$ & 0.0 \\
\hline \multicolumn{9}{|l|}{ Lantana } \\
\hline WR-SMC & 71.0 & 32.2 & 8 & $\mathrm{~b}$ & 11.1 & 3.1 & $\mathrm{a}$ & 11.0 \\
\hline NR-SMC & 48.0 & 0.0 & 9 & $\mathrm{a}$ & 0.0 & 3.5 & $\mathrm{a}$ & 0.0 \\
\hline \multicolumn{9}{|c|}{ Impatiens SCC } \\
\hline WR-SMC & 81.0 & 6.8 & 7 & $\mathrm{~b}$ & 22.2 & 2.9 & $\mathrm{~b}$ & 23.2 \\
\hline NR-SMC & 76.0 & 0.0 & 9 & $\mathrm{a}$ & 0.0 & 3.8 & $\mathrm{a}$ & 0.0 \\
\hline \multicolumn{9}{|c|}{ Impatiens SSL } \\
\hline WR-SMC & 67.0 & -0.5 & 7 & $\mathrm{~b}$ & 12.5 & 3.8 & $\mathrm{a}$ & -8.2 \\
\hline NR-SMC & 67.0 & 0.0 & 8 & $\mathrm{a}$ & 0.0 & 3.5 & $\mathrm{a}$ & 0.0 \\
\hline \multicolumn{9}{|l|}{ Salvia } \\
\hline WR-SMC & 78.0 & 13.4 & 7 & $\mathrm{~b}$ & 36.4 & 3.9 & $\mathrm{~b}$ & 33.1 \\
\hline NR-SMC & 67.0 & 0.0 & 11 & $\mathrm{a}$ & 0.0 & 5.9 & $\mathrm{a}$ & 0.0 \\
\hline
\end{tabular}

${ }^{\mathrm{z}}$ Estimated container number/bench was calculated as standard bench size $\left(19.5^{\prime} \times 5.5^{\prime}\right)$ /average canopy size of the plant.

${ }^{\mathrm{y}}$ Space saved was calculated based on the difference in the final spacing between WR-SMC and NR-SMC.

${ }^{\mathrm{x}}$ Total no. of irrigation events during production weeks.

${ }^{\mathrm{w}}$ Means separation by Student t-test at $P \leq 0.05$. Means with the same letter are not different.

${ }^{\mathrm{v}}$ Labor saved was calculated based on the difference in the number of irrigation events between WR-SMC and NR-SMC.

${ }^{\mathrm{u}}$ Total irrigation amount per container was the sum of each irrigation water input during 8 weeks of greenhouse production.

${ }^{\mathrm{t}}$ Irrigation amount saved was calculated based on the difference in the total irrigation amount between WR-SMC and NR-SMC.

lower SPAD reading at the end of production and postproduction (Fig. 4). SPAD is directly related to leaf thickness, nitrogen concentration, chlorophyll level, and water status (Basyouni et al., 2015; Martínez and Guiamet, 2004). In our study, the higher SPAD with NR-SMC for lantana could have been related to the higher leaf nitrogen concentration associated with higher-frequency watering and, therefore, fertilization with each irrigation event because no difference in leaf thickness was detected in any of the cultivars (data not shown). The higher SPAD reading for petunia and salvia with WR-SMC could have been due to lower leaf water content or increased leaf chlorophyll content (Martínez and Guiamet, 2004).

The water potential for coleus, petunia, lantana, and salvia was greater with NR-SMC during production. During postproduction, the water potential for coleus, petunia, and lantana was greater with WR-SMC, whereas that for salvia was unaffected by SMC
(Fig. 5), indicating that WR-SMC during production increased water stress for all four species and reduced water stress during postproduction for coleus, petunia, and lantana. Midday water potential is commonly used as a reliable indicator of plant water stress severity (Jones, 2006; Kim et al., 2012; Shackel et al., 1997). During production weeks, plants with WR-SMC had a higher stress level. Similar results were reported for petunia, vinca, and rose (Kim et al., 2012; Kim and van Iersel, 2011). Our study was significant because WR-SMC during production decreased the water stress level of coleus, lantana, and petunia during postproduction, indicating a possible acclimation to water stress when plants are allowed to repeatedly dry down from $\mathrm{CC}$ to $20 \%$ SMC during production.

Visual quality. At the end of production, petunia, lantana, and impatiens SSL shoot coloring percentages were unaffected by SMC treatment; however, it was greater with
NR-SMC for impatiens SCC (Table 4). At the end of postproduction, petunia with WRSMC had a greater shoot coloring percentage, but lantana and impatiens SCC with NRSMC had a greater shoot coloring percentage, and impatiens SSL shoot coloring percentage was unaffected (Table 4; Fig. 6).

Petunia with WR-SMC had a higher shoot coloring percentage during postproduction because of the increased flower number. Lantana with WR-SMC had a lower shoot coloring percentage due to the lower flower number during postproduction. Impatiens SCC with WR-SMC produced fewer buds; therefore, it had a lower shoot coloring percentage. Impatiens SSL flower number and bud number were unaffected by SMC treatment, as were their shoot coloring percentages.

At the end of production, salvia visual quality was not different between SMC treatments, except NR-SMC resulted in an increased vegetative stem segment with leaves 
Table 7. Postproduction irrigation and associated economic implications of Solenostemon scutellarioides 'French Quarter', Petunia $\times$ hybrida 'Colorworks Pink Radiance', Lantana camara 'Lucky Flame', and Impatiens Xhybrida 'Sunpatiens Compact Hot Coral' (SCC) in 2017; 'Sunpatiens Spreading Lavender' (SSL) and Salvia splendens 'Red Hot Sally II' in 2018, grown at one of two substrate moisture contents (SMC): (1) wide range (WR) (54\% to 20\% SMC); and, narrow range (NR) (54\% to $40 \%$ SMC) during 2 weeks of simulated shelf life.

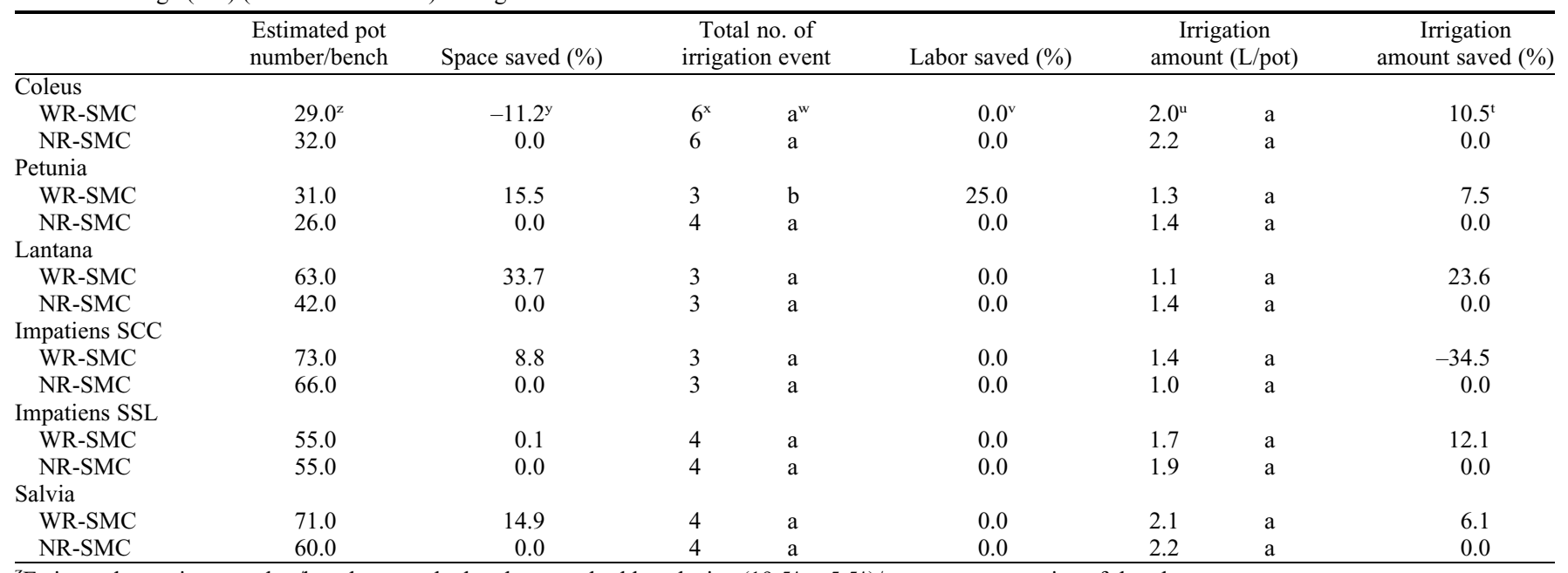

${ }^{\mathrm{z}}$ Estimated container number/bench was calculated as standard bench size $\left(19.5^{\prime} \times 5.5^{\prime}\right) /$ average canopy size of the plant.

${ }^{\mathrm{y}}$ Space saved was calculated based on the difference in final spacing between WR-SMC and NR-SMC.

${ }^{\mathrm{x}}$ Total no. of irrigation events during 2 weeks of postproduction simulated shelf life.

${ }^{\text {w}}$ Means were separated by Student $t$-test at $P \leq 0.05$. Means with the same letter are not different.

${ }^{\vee}$ Labor saved was calculated based on the difference in the number of irrigation events between WR-SMC and NR-SMC.

"Total irrigation amount per container was the sum of each irrigation water input during 2 weeks of postproduction simulated shelf life.

tIrrigation amount saved was calculated based on the difference in the total irrigation amount between WR-SMC and NR-SMC.

compared with that treated with WR-SMC, thereby increasing the total stem height. After 2 weeks of postproduction, salvia with NRSMC had increased abscised leaves, abscised flowers, and numbers of senesced inflorescences and chlorotic leaves (Table 5).

Previous research showed that using less SMC produced Salvia splendens with higher visual quality and improved tolerance to low SMC compared with untreated plants (Eakes et al., 1991). Drought-induced leaf abscission was believed to contribute to plant survival under water deficit conditions by relocating nutrients to the rest of the plant and reducing water loss through leaf transpiration. Chlorophyll degradation led to leaf chlorosis as part of the process of drought-induced leaf abscission (Munné-Bosch and Alegre, 2004). In our research, even though salvia water potential was not different between SMC treatments during postproduction, plants with NR-SMC had higher chlorotic leaf numbers and increased segments of vegetative stems with abscised leaves. This indicated that they had a more severe response to a water deficit during postproduction compared with plants with WR-SMC. When combined with lower inflorescence quality, this indicated that plants with NR-SMC declined faster during postproduction.

Irrigation and associated economic implications. In this study, we considered NR-SMC equivalent to the traditional, wellirrigated method that is currently used by floral industry growers for potted plant production. Compared with those treated with NR-SMC, lantana, impatiens SCC, petunia, and salvia treated with WR-SMC had a smaller canopy; therefore, they required less bench space, which may translate to lower overhead costs associated with bench space (because they are normally applied based on the number of square feet per week). Compared to those treated with NR-SMC, coleus, petunia, lantana, impatiens SCC, and salvia saved $7.8 \%, 24.1 \%, 32.2 \%, 6.8 \%$, and $13.4 \%$ on bench space, respectively, during production (Table 6). Impatiens SSL canopy size was unaffected by SMC treatments; therefore, no overhead space was saved. During the production weeks, WR-SMC required fewer total irrigation events; therefore, coleus, petunia, lantana, impatiens SCC, and salvia saved $8.3 \%, 27.3 \%, 11.1 \%, 22.2 \%$, $12.5 \%$, and $36.4 \%$ on irrigation-related labor, respectively. Although coleus, petunia, lantana, and impatiens SSL grown in WR-SMC required fewer total irrigation events, the irrigation amount used was unaffected by SMC (Table 6).

During postproduction, petunia, lantana, impatiens SCC, and salvia grown in WRSMC saved $15.5 \%, 33.7 \%, 8.8 \%$, and $14.9 \%$ on bench space, respectively. Coleus with WR-SMC required more bench space than coleus with NR-SMC. Impatiens SSL bench space was the same regardless of the SMC treatment used. Only petunia saved $25 \%$ on irrigation-related labor when the total number of irrigation events for other cultivars was unaffected by the SMC treatment. For all six cultivars, the postproduction irrigation amount was unaffected by SMC (Table 7).

These results showed that costs of production can be reduced by using less frequent irrigation events compared with more frequent irrigation events. The reductions in costs are a result of the reduced bench space required (which reduced the residency costs expressed by overhead cost per square foot per week), the reduced amount (and associated costs) of water, and the reduced irrigation-associated labor (e.g., to check and repair emitters). For all six cultivars, the total number of irrigation events was less with WR-SMC during production weeks, but the total irrigation water usage was not reduced with less frequent irrigation, with the exception of petunia and salvia. The irrigation amount was not different when the numbers of irrigation events were different because at the time of irrigation, the containers that were allowed to dry down to $20 \%$ SMC were drier compared with $40 \%$ $\mathrm{SMC}$; therefore, they needed more water input at each irrigation event to increase the SMC back to CC. For short-season crops with higher water-use requirements, the total water input may not be different between SMC types.

\section{Conclusion}

Responses and acclimation to WR-SMC varied among cultivars. Petunia and impatiens SCC with WR-SMC had higher root ball coverage percentages, whereas impatiens SSL and salvia with WR-SMC had lower root ball coverage percentages. The WR-SMC reduced lantana and impatiens SCC postproduction quality by reducing flower numbers and/or bud numbers. Coleus and impatiens SSL morphology was unaffected by SMC. Coleus, petunia, and lantana showed that plants with WR-SMC had decreased water stress (less negative water potential) during postproduction, indicating that plants exposed to a mild water deficit during production were acclimated to water stress.

The WR-SMC reduced the total number of irrigation events for all four species tested, 
but it did not affect the irrigation volume delivered to coleus, petunia, lantana, and impatiens SSL. However, WR-SMC saved labor during production for all six cultivars and reduced bench space, with the exception of coleus and impatiens SSL. Based on the partial budget modeling procedures we used in this experiment, WR-SMC proved to be a more cost-efficient production method for all six bedding plant cultivars grown in 1.67-L containers. However, considering the crop quality and flower number, WR-SMC is not recommended for lantana 'Lucky Flame' and impatiens SCC produced in a greenhouse. Our results suggested that using WR-SMC is the best-practice irrigation method for these cultivars of coleus, petunia, impatiens SSL, and salvia during greenhouse production.

\section{Literature Cited}

Alem, P., P.A. Thomas, and M.W. van Iersel. 2015. Substrate water content and fertilizer rate affect growth and flowering of potted petunia. HortScience 50:582-589.

Álvarez, S., S. Bañón, and M.J. Sánchez-Blanco. 2013. Regulated deficit irrigation in different phenological stages of potted geranium plants: Water consumption, water relations and ornamental quality. Acta Physiol. Plant. 35:12571267.

Álvarez, S., A. Navarro, S. Bañón, and M.J. Sánchez-Blanco. 2009. Regulated deficit irrigation in potted Dianthus plants: Effects of severe and moderate water stress on growth and physiological responses. Scientia Hort. 122:579-585.

Álvarez, S., A. Navarro, E. Nicolás, and M.J. Sánchez-Blanco. 2011. Transpiration, photosynthetic responses, tissue water relations and dry mass partitioning in callistemon plants during drought conditions. Scientia Hort. 129: 306-312.

Álvarez, S. and M.J. Sánchez-Blanco. 2013. Changes in growth rate, root morphology and water use efficiency of potted Callistemon citrinus plants in response to different levels of water deficit. Scientia Hort. 156:54-62.

Basyouni, R., B.L. Dunn, and C. Goad. 2015. Use of nondestructive sensors to assess nitrogen status in potted poinsettia [Euphorbia pulcherrima L. (Willd. ex Klotzsch)] production. Scientia Hort. 192:47-53.

Bayer, A., J. Ruter, and M.W. van Iersel. 2015. Automated irrigation control for improved growth and quality of Gardenia jasminoides 'Radicans' and 'August Beauty'. HortScience 50:78-84.

Blanusa, T., E. Vysini, and R.W.F. Cameron. 2009. Growth and flowering of petunia and impatiens: Effects of competition and reduced water content within a container. HortScience 44:1302-1307.

Blum, A. 1996. Crop responses to drought and the interpretation of adaptation, p. 57-70. Drought tolerance in higher plants: Genetical, physiol. and molecular biological analysis. Springer.

Boyer, J.S. 1970. Leaf enlargement and metabolic rates in corn, soybean, and sunflower at various leaf water potentials. Plant Physiol. 46(2):233-235.
Burnett, S., P. Thomas, and M. van Iersel. 2005. Postgermination drenches with PEG-8000 reduce growth of salvia and marigolds. HortScience 40:675-679.

Burnett, S.E. and M.W. van Iersel. 2008. Morphology and irrigation efficiency of Gaura lindheimeri grown with capacitance sensor-controlled irrigation. HortScience 43:1555-1560.

Cai, X., T. Starman, G. Niu, and C. Hall. 2014. The effect of substrate moisture content on growth and physiological responses of two landscape roses (Rosa hybrida L.). HortScience 49:741-745.

Cai, X., T. Starman, G. Niu, C. Hall, and L. Lombardini. 2012. Response of selected garden roses to drought stress. HortScience 47:10501055.

Chyliński, W.K., A.J. Łukaszewska, and K. Kutnik. 2007. Drought response of two bedding plants. Acta Physiol. Plant. 29(5):399-406.

Dole, J.M. and H.F. Wilkins. 1999. Floriculture: Principles and species. Prentice-Hall Inc. Upper Saddle River, NJ.

Eakes, D.J., R.D. Wright, and J.R. Seiler. 1991. Moisture stress conditioning effects on Salvia splendens 'Bonfire'. J. Amer. Soc. Hort. Sci. 116:716-719.

Fonteno, W., C. Hardin, and J. Brewster. 1995. Procedures for determining physical properties of horticultural substrates using the NCSU Porometer. Hort. Substrates Lab., N.C. State Univ.

Garland, K.F., S.E. Burnett, M.E. Day, and M.W van Iersel. 2012. Influence of substrate water content and daily light integral on photosynthesis, water use efficiency, and morphology of Heuchera americana. J. Amer. Soc. Hort. Sci. 137:57-67.

Guo, Y., T. Starman, and C. Hall. 2018. Reducing substrate moisture content (SMC) during greenhouse production and postproduction of angelonia and heliotrope improves crop quality and economic value. HortScience 53:1-6.

Islam, M.A. and D.C. Joyce. 2015. Postharvest behavior and keeping quality of potted poinsettia: A review. Res. Agr. Livestock and Fisheries 2(2):185-196.

Jacobson, A.B., T.W. Starman, and L. Lombardini. 2015. Substrate moisture content effects on growth and shelf life of Angelonia angustifolia. HortScience 50:272-278.

Jaleel, C.A., R. Gopi, B. Sankar, M. Gomathinayagam, and R. Panneerselvam. 2008. Differential responses in water use efficiency in two varieties of Catharanthus roseus under drought stress. C. R. Biol. 331(1):42-47.

Jones, H.G. 2006. Monitoring plant and soil water status: Established and novel methods revisited and their relevance to studies of drought tolerance. J. Expt. Bot. 58(2):119-130.

Kim, J., A. Malladi, and M.W. van Iersel. 2012. Physiological and molecular responses to drought in petunia: The importance of stress severity. J. Expt. Bot. 63(18):6335-6345.

Kim, J. and M.W. van Iersel. 2009. Daily water use of abutilon and lantana at various substrate water contents. Proc. SNA Res. Conf. 54.

Kim, J. and M.W. van Iersel. 2011. Slowly developing drought stress increases photosynthetic acclimation of Catharanthus roseus. Physiol. Plant. 143(2):166-177.

Martínez, D. and J. Guiamet. 2004. Distortion of the SPAD 502 chlorophyll meter readings by changes in irradiance and leaf water status. Agronomie 24:41-46.

Munné-Bosch, S. and L. Alegre. 2004. Die and let live: Leaf senescence contributes to plant survival under drought stress. Funct. Plant Biol. 31(3):203-216.

Nemali, K.S. and M.W. van Iersel. 2006. An automated system for controlling drought stress and irrigation in potted plants. Scientia Hort. 110:292-297.

Nemali, K.S. and M.W. van Iersel. 2008. Physiological responses to different substrate water contents: Screening for high water-use efficiency in bedding plants. J. Amer. Soc. Hort. Sci. 133:333-340.

Niu, G., D.S. Rodriguez, L. Rodriguez, and W. Mackay. 2007. Effect of water stress on growth and flower yield of big bend bluebonnet. HortTechnology 17:557-560.

Niu, G., D.S. Rodriguez, and W. Mackay. 2008. Growth and physiological responses to drought stress in four oleander clones. J. Amer. Soc. Hort. Sci. 133:188-196.

Niu, G., D.S. Rodriguez, and Y.-T. Wang. 2006. Impact of drought and temperature on growth and leaf gas exchange of six bedding plant species under greenhouse conditions. HortScience 41:1408-1411.

Sakata Seed America. 2017. Sunpatiens culture guide. Sakata Seed America, Inc. 4 July 2018. $<$ https://sakataornamentals.com/wp-content/ uploads/sites/2/2018/05/SunPatiensCultureGuide December2017.pdf $>$.

Sánchez-Blanco, M.J., S. Álvarez, A. Navarro, and S. Bañón. 2009. Changes in leaf water relations, gas exchange, growth and flowering quality in potted geranium plants irrigated with different water regimes. J. Plant Physiol. 166:467-476.

Sato, C. and S. Minemura. 2014. New Guinea impatiens plant named 'SAKIMP026'. U.S. Patents Application. 4 July 2018. <https:// patents.google.com/patent/USPP24321P2/en>.

Sato, C. and S. Minemura. 2016. New Guinea impatiens plant named 'SAKIMP034'. Patents Application. 4 July 2018. <https://patents. google.com/patent/USPP26693P2/en>.

Shackel, K.A., H. Ahmadi, W. Biasi, R. Buchner, D. Goldhamer, S. Gurusinghe, J. Hasey, D. Kester, B. Krueger, and B. Lampinen. 1997. Plant water status as an index of irrigation need in deciduous fruit trees. HortTechnology 7:2329.

Taiz, L., E. Zeiger, I.M. Møller, and A. Murphy. 2015. Plant physiology and development. Sinauer Associates, Inc. Sunderland, MA.

Tezara, W., V. Mitchell, S. Driscoll, and D. Lawlor. 1999. Water stress inhibits plant photosynthesis by decreasing coupling factor and ATP. Nature 401(6756):914.

USDA. 2016. National Agricultural Statistics Service, U.S. Dept. 26 Apr. 2016. <http://usda. mannlib.cornell.edu/usda/current/FlorCrop/ FlorCrop-04-26-2016.pdf $>$.

Wegley, J. 2007. Plant of the month: SunPatiens. Neil Sperry's Gardens, Dallas Arboretum Plant Trials. 27 Aug. 2018. <http://www.dallasplanttrials.org/index.cfm/fuseaction/articles.detail/ articleID/92/index.htm $>$.

Wright, R.D. 1986. The pour-through nutrient extraction procedure. HortScience 21:227229. 